\title{
Giant Retropharyngeal Abscess in a Nigerian Adult Following Fish Bone Throat Injury
}

\author{
Stanley B. Amutta ${ }^{1 *}$, Daniel Aliyu ${ }^{1}$, Mohammed Abdullahi ${ }^{1}$, Mohammed Danfulani ${ }^{2}$, \\ Yunusa A. Mufutau ${ }^{3}$ \\ ${ }^{1}$ ENT Department, Usmanu Danfodiyo University Teaching Hospital, Sokoto, Nigeria \\ ${ }^{2}$ Radiology Department, Usmanu Danfodiyo University Teaching Hospital, Sokoto, Nigeria \\ ${ }^{3}$ Psychiatry Department, Usmanu Danfodiyo University Teaching Hospital, Sokoto, Nigeria \\ Email: *samutta14@gmail.com
}

Received August 26, 2013; revised September 25, 2013; accepted October 6, 2013

Copyright (C) 2013 Stanley B. Amutta et al. This is an open access article distributed under the Creative Commons Attribution License, which permits unrestricted use, distribution, and reproduction in any medium, provided the original work is properly cited.

\begin{abstract}
Retropharyngeal abscess (RPA) is an uncommon disease entity that typically occurs in children under 5 years of age, which has the potential to cause upper airway obstruction. Upper respiratory tract infection is the most common predisposing factor to RPA in children while cervical spine tuberculosis and trauma are the major aetiological factors in the adult. We report a case of a 21-year-old Nigerian farmer with giant retropharyngeal abscess following fish bone throat injury causing life-threatening upper airway obstruction. The patient responded well to emergency tracheostomy, intraoral surgical drainage and empirical antibiotic therapy. We highlight the diagnostic and therapeutic challenges of managing such a patient.
\end{abstract}

Keywords: Giant Retropharyngeal Abscess; Fish Bone; Tracheostomy; Antibiotic; Intra-Oral Drainage

\section{Introduction}

Retropharyngeal abscess (RPA) though an uncommon disease entity occurs usually in children under the age of 5 years [1-3]. However, recent findings indicate that adults could also be involved [4,5]. The involvement of the airway results in upper airway obstruction which could lead to life threatening condition thus, it is a surgical emergency. The pathological basis for the higher prevalence in children is due to the loose aggregate of lymph nodes in the prevertebral space which may become infected with resultant suppuration. These lymph nodes are not usually present in adults because they atrophy while the child grows; hence retropharyngeal abscess is not a common disorder among adults. Upper respiratory tract infection is the most common predisposing factor to RPA in children [3-6] while cervical spine tuberculosis and trauma are the major aetiological factors in adults [3-5,7]. Other factors reported among adults include diabetes mellitus [4] and human immunodeficiency virus (HIV) infection [7,8].

In a retrospective study in Ibadan, Nigeria [9], thirty cases of retropharyngeal abscess were reported compris-

${ }^{*}$ Corresponding author. ing of 25 children and 5 adults. In that study, adult patients presented early while the children presented late. A recent study from north central Nigeria reported RPA due to fish bone but in a child [5]. We report a case of giant retropharyngeal abscess in a 21-year-old subsistence adult Nigerian farmer following fish bone throat injury while highlighting the diagnostic and therapeutic challenges of managing this type of patient.

\section{Case Report}

A 21-year-old subsistence farmer, presented at the Emergency department of our hospital with 10-day history of progressive sore throat, persistent low grade fever, neck pain, dyspnoea, odynophagia and voice changes. There was an antecedent history of fish bone impaction in the throat two weeks prior to the onset of symptoms however; the patient did not seek medical intervention. He was unable to take both fluid and solid diet at presentation. There was associated hoarseness and inability to sit or stand without support. There was no history suggestive of recurrent tonsillitis, dental infection, chronic cough, night sweats or contact with a patient with pulmonary tuberculosis and was not a known diabetic. 
Examination revealed an acutely ill-looking young man in painful and respiratory distress, was dehydrated, in stridor, with inaudible hoarse voice, limitation of neck movement and also had trismus. He was not pale and there was no significant peripheral lymphadenopathy. There was no impairment in the mental state. Vital signs were blood pressure of $90 / 60 \mathrm{mmHg}$, pulse rate of $96 /$ minute, respiratory rate of $30 /$ minute and temperature was $37.4^{\circ} \mathrm{C}$.

Ear and nasal examinations were essentially normal. There was moderate trismus and poor oral hygiene, but there was no evidence of dental infection. Examination of the posterior pharyngeal wall was difficult due to trismus and neck pain. There was remarkable decreased air entry in both lung fields with wide spread transmitted sounds. Heart sounds were I and II were essentially normal. Abdominal and central nervous system examinations were normal and there was no cervical spine tenderness or gibbous deformity.

A provisional diagnosis of upper airway obstruction secondary to deep neck space infection possibly secondary to retropharyngeal abscess was made to rule out peritonsillar and parapharyngeal abscesses. The patient had X-ray of the neck with a conventional X-ray machine Silhouette VR GE 2007 using automatic processor, Colenta 2007 model 2226680/MS18s serial number 48202HL6, with inherent filtration of $0.6 \mathrm{mmAL}$ and additional filtration of $1.0 \mathrm{mmAL}$. The X-ray soft tissue neck lateral view showed the reversal of the normal cervical curvature with a huge soft tissue mass in the retrotrachael space displacing the trachea anteriorly with significant associated luminal narrowing. This soft tissue mass measured about $65 \mathrm{~mm}$ at its widest point at the level of $4^{\text {th }}$ cervical vertebra (C4). The anteroposterior view also showed huge soft tissue mass around its mid portion. No areas of calcifications or lucencies were demonstrated within the soft tissue mass. Overall, features of the X-ray of the neck were those of a huge retropharyngeal mass lesion, presumably retropharyngeal abscess. These radiological features further supported the provisional diagnosis of RPA (Figure 1). The soft tissue, bony framework of the chest, lung fields and heart appeared normal on Chest X-ray. Patient could not do computerized tomography (CT) scanning due to financial constraints.

Other laboratory studies showed packed cell volume of $40 \%$, random blood sugar $6.4 \mathrm{mmol} / \mathrm{L}$, serum electrolytes, urea and creatinine were within normal limits. Screening for HIV I and II using ELISA (enzyme linked immunoabsorbent assay) was non-reactive. White blood cell count was elevated and demonstrated neutrophilia while the erythrocyte sedimentation rate (ESR) was 15 $\mathrm{mm} / \mathrm{hr}$ Westergreen.

Patient was rehydrated and intravenous cefuroxime 1

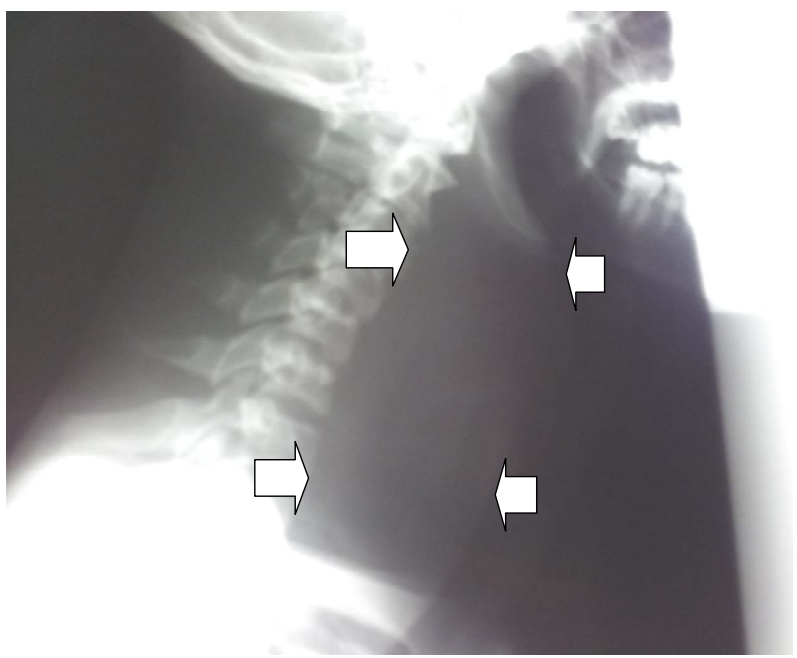

Figure 1. Lateral view, soft tissue $X$-ray of the neck showing grossly increased prevertebral soft tissue shadow delineated by white arrows.

gram 12-hourly, metronidazole $500 \mathrm{mg} 8$-hourly; paracetamol $300 \mathrm{mg}$ 8-hourly and diclofenac sodium $50 \mathrm{mg}$ 8 -hourly were administered. Emergency tracheostomy was done under local anaesthesia infiltration with $2 \%$ xylocaine 1:200,000 adrenaline to relieve the life threatening upper airway obstruction and the procedure continued with administration of general anaesthesia via the tracheostomy tube. He was then placed in Rose position and the oropharynx was exposed with Davis-Boyle gag frame.

Operative findings were grossly enlarged posterior pharyngeal wall which was tense and fluctuant and 500 mls of thick pus under tension was drained via a vertical incision. The abscess cavity was irrigated with warm normal saline and a feeding nasogastric tube (NGT) was passed. The specimen from the abscess cavity was sent for microscopy, culture and sensitivity and Ziehl-Neelsen (ZN) staining for acid-fast bacilli (AFB). The specimen yielded florid pus cells, but no bacterial growth and the $\mathrm{ZN}$ stain was negative for AFB.

Post operatively the patient had intravenous cefuroxime, metronidazole, paracetamol and diclofenac sodium for 72 hours, and this was changed to oral cefuroxime and metronidazole which were administered via the NGT for further 7-days. He had NGT feeding for the first five days post operative period, started feeding around the NGT from the $6^{\text {th }}$ day after the surgical drainage, and the NGT was finally removed on the $16^{\text {th }}$ day after surgery as oral feeding was adequately restored. He was decanulated on the $8^{\text {th }}$ post operative day when post operative lateral radiograph of the neck showed only straightening of the cervical spine with significant reduction of the retrotrachael space, and reversal of the narrowed airways in comparison with the previous examination (Figures 1 and 2). The retrotrachael space at the 


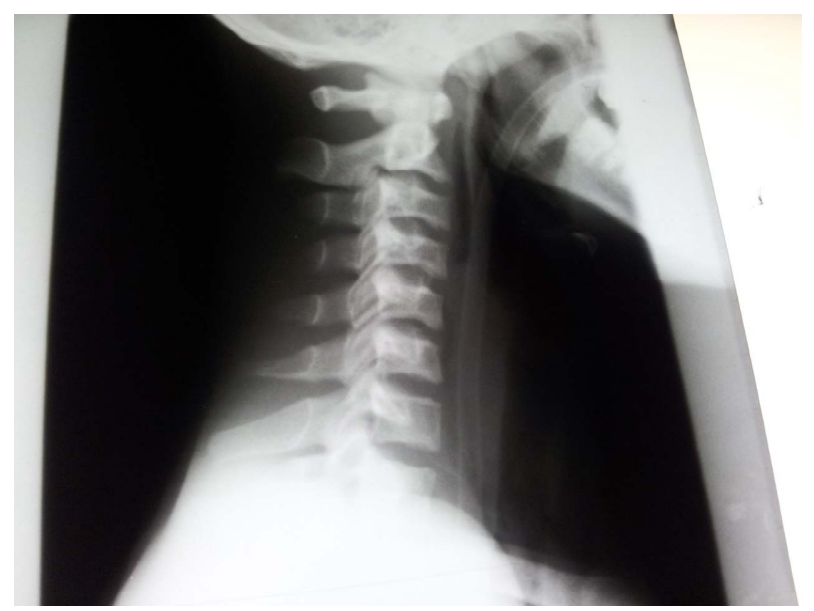

Figure 2. Lateral view, post operative soft tissue $X$-ray of the neck with nasogastric tube in situ and resolution of the increased prevertebral soft tissue shadow.

level of $\mathrm{C} 4$ was reduced to about $20 \mathrm{~mm}$ (Figure 2) and no recurrence on follow-up visit.

\section{Discussion}

The retropharyngeal space is one of the deep neck spaces with the skull base as the superior border, the inferior and the posterior limits are the superior mediastinum and the prevertebral fascia respectively while the posterior border of the pretrachael fascia forms the anterior border. Laterally, it is bounded by the carotid sheath and it contains lymph nodes [10]. RPA may present with life threatening upper airway obstruction, as it was in our index patient [1-5,9]. Delay in the diagnosis of RPA is often associated with other serious morbidities such as aspiration pneumonia, sepsis, mediastinitis, empyema and erosion of carotid artery [4,6,11]. The diagnosis is usually made based on clinical symptoms, signs as well as radiological features. However, these symptoms and signs are non-specific to retropharyngeal abscess [6]. In adults RPA may present with fever, sore throat, odynophagia, dysphagia, drooling, and dyspnoea and muffled voice. Signs of the disease include limitation of neck movement, torticolis, cervical tenderness, bulging posterior oropharyngeal wall, increased prevertebral soft tissue shadow on plain lateral neck X-ray and contrast enhanced CT scanning may demonstrate the extent of the abscess [1,2]. Our patient presented with most of these clinical and plain X-ray features of RPA. The grossly increased prevertebral soft tissue shadow was the indicator for the provisional diagnosis of RPA in this index case. The use of X-ray for this purpose is limited and controversial because of its inability to differentiate inflammatory oedema from abscess.

It was not possible to delineate the extent of the abscess or involvement of other deep neck spaces before the surgical drainage. Contrast enhanced CT scanning would have made this possible, $[1-4,6]$ but it was not done to avoid further delay of the worsening severe upper airway obstruction and besides, the patient could not afford to pay for the CT scan at presentation which costs $\$ 20000.00$ (about \$130.00) as he was not covered by any health insurance because he was not in federal civil service as this is the main agent providing health insurance cover for Nigerians. Furthermore, in a resource limited society with prevalent poverty, clinical history, physical examinations and X-ray findings still form the basis for the diagnosis of RPA [5] as in this case report.

It is important to consider the differential diagnosis in a patient with suspected RPA before initiating any treatment options. Congenital cystic lesions like infected branchial cleft cyst, thyroglossal duct cyst and cervical thymic cyst may mimic or be the source of a deep neck abscess [12]. Incision and drainage make definitive excision of these cysts cumbersome. Additionally, malignant head and neck cancers, and lymphoma may metastasize to cervical lymph node and present with deep neck space infection or abscess [12]. Therefore, high index of suspicion is suggested for prompt diagnosis. Epiglottitis, sialoadenitis and infected laryngocele have been implicated in the development of deep neck abscesses [13]. Calcific retropharyngeal tendinitis and RPA [14] have similar clinical features. Contrast enhanced CT scan features of calcific retropharyngeal tendinitis includes increased prevertebral soft tissue mass with calcification and it does not require surgical drainage as it responds very well to non-steroidal anti-inflammatory drugs and steroid [14].

Treatment of RPA includes rehydration, intravenous antibiotic and surgical drainage under general anaesthesia administered by an experienced anaesthetist $[1,2,12$, $15,16]$. Provision of adequate airway is a priority in a patient with RPA and life threatening upper airway obstruction; hence, the patient in this report had emergency tracheostomy under local anaesthesia before the surgical drainage of the abscess. This is in agreement with other reports $[3,15]$. In addition, tracheostomy may be used in the absence of upper airway obstruction to prevent accidental rupture of the abscess during intubation by an inexperienced anaesthetist [3] and in addition, compromised airways resulting from post operative oedema is another indication for routine tracheostomy in these patients.

The surgical approaches for drainage of RPA are transoral, transcervical, transnasal endoscopic or combined approach [15]. The transoral approach is usually recommended for acute RPA and those located medially [15]. This approach yields good result and avoids a neck incision and the subsequent scar [15] however it requires administration of general anaesthesia. 
Trans-nasal endoscopic guided needle aspiration is suitable for very small and unilocular abscesses [15-17]. It has the advantage of avoiding general anaesthesia and probable injury to local structures such as blood vessels and nerves [17], although repeated aspirations may be required to achieve complete resolution. Additionally, it is not appropriate for large abscesses with potential for airways obstruction [17]. Cold RPA from tuberculosis is drained by external transcervical approach to prevent dissemination of the infection into the gastrointestinal tract. Besides, large or recurrent acute RPA that extend behind carotid artery can be safely approach by the transcervical route [17] to limit bleeding. Disadvantages are neck scar and injury to surrounding structures.

The main aetiological factors of RPA in adult are trauma induced by foreign bodies, iatrogenic, orodental infection and tuberculosis [3,4,6-8]. Fish bone injury was the responsible agent in our index patient. It is important to note that the patient did not seek medical help until complications set in thus compelling him to come to the hospital. Ignorance coupled with poverty and poor access to specialist otolaryngologic service was some of the reasons that hindered the patient from seeking medical care early. In contrast to this, adults with RPA in another report from Western Nigeria presented early [9]. The high level of awareness, better economic environment and exposure to western education in western region of Nigeria may be the explanation for this difference.

Clinical conditions associated with impaired immunity such as tuberculosis, diabetes mellitus and infection with HIV which are relatively common in developing countries are sometimes associated with RPA [18-21]. The patient in this report did not have destructive lesion of the cervical vertebra and Ziehl-Neelsen staining of the specimen smear for acid-fast bacilli was negative while random blood sugar value was within normal range and he was non-reactive to HIV I and II viruses.

The organisms frequently encountered in RPA are polymicrobial including aerobes (group A $\beta$-haemolytic streptococcus, staphylococcus aureus and haemophilus influenza), anaerobes (gram negative cocci and bacteroides) $[11,22]$. The specimen from our patient yielded no bacterial growth. This could be due to prior antibiotic therapy from rural patent medicine shops which is a common practice by our patients though inappropriate culture technique and media for the isolation of anaerobes could be responsible.

The retropharyngeal abscess was described as giant because it measured $65 \mathrm{~mm}$ in diameter and this so far the biggest reported from our sub-region. However, we could not verify if larger size has been reported elsewhere. In an earlier report Ozbek et al., [3] reported a giant RPA which was $61 \mathrm{~mm}$ in transverse diameter but this is smaller than that reported in the present case.
The prognosis for patients with RPA is very good especially with early diagnosis and appropriate intervention. However, with late presentation, delayed diagnosis and in the presence of significant co-morbidities such as immunosuppression, HIV, tuberculosis, diabetes mellitus, head and neck malignancies the prognosis may be poor. Ridder et al. [12] reported 6 (2.6\%) mortality among 234 cases over an 8-year period and the deaths were due to sepsis and multiple organ failure. Overall, the patient in this report responded very well to the tracheostomy, intra-oral drainage and the broad spectrum antibiotics. He was decanulated on the $8^{\text {th }}$ day post surgical drainage and was discharged home after achieving full recovery and no recurrence on follow-up visit.

\section{Conclusion}

The prognosis of giant retropharyngeal abscess is good with tracheostomy, surgical drainage and medical intervention as seen in this case report.

\section{REFERENCES}

[1] B. Hartley, "Cervicofacial Infection in Children," In: G. Michael, Ed., Scott's Browns Otorhinolaryngology, Head and Neck Surgery, 7th Edition, Hodder Arnold, London, 2008, pp. 1213-1214.

http://dx.doi.org/10.1201/b15118-107

[2] L. W. Tom and I. N. Jacobs, "Diseases of the Oral Cavity, Oropharynx, and Nasopharynx," In: B. James, Ed., Ballenger's Otorhinolaryngology, Head and Neck Surgery, 16th Edition, BC Decker Inc., Hamilton, 2003, pp. 1039-1040.

[3] C. Ozbek, S. Dagli, E. E. U. Tuna, O. Ciffci and C. Ozdem, "Giant Retropharyngeal Abscess in an Adult as a Complication of Acute Tonsillitis: Case Report," Ear Nose Throat Journal, Vol. 88, No. 11, 2009, p. E20.

[4] S. B. Sharma and P. Hong, "Ingestion and Pharyngeal Trauma Causing Secondary Retropharyngeal Abscess in Five Adult Patients," Case Report in Emergency Medicine, Vol. 2012, 2012, Article ID: 943090.

[5] O. A. Afolabi, J. O. Fadare, E. O. Oyewole and S. A. Ogah, "Fish Bone Foreign Body Presenting with an Acute Fulminating Retropharyngeal Abscess in a ResourceChallenge Centre: A Case Report," Journal of Medical Case Reports, Vol. 5, 2011, p. 165. http://dx.doi.org/10.1186/1752-1947-5-165

[6] A. Harkani, R. Hassani, T. Ziad, L. Aderdour, H. Nouri, Y. Rochdi and A. Raji, "Retropharyngeal Abscess in Adults: Five Case Reports And Review of the Literature," The Scientific World Journal, Vol. 11, 2011, pp. 16231629. http://dx.doi.org/10.1100/2011/915163

[7] E. Mevio, P. Calabro, F. De Paoli, A. Maccabruni and G. Michelone, "Unusual Extracranial Complications of Otitis Media in a Young HIV Patient: Retropharyngeal and Mouret's Abscess," Revue de Laryngologie-OtologieRhinologie, Vol. 119, No. 3, 1998, pp. 199-201.

[8] R. Meyer, S. Argarwal and I. Singh, "Tuberculous Retro- 
pharyngeal Abscess in an HIV Patient," Hong Kong Medical Journal, Vol. 12, No.6, 2006, pp. 483-485.

[9] O. G. Nwaorgu, P. A. Onakoya, J. A. Fasunla and T. S. Ibekwe, "Retropharyngeal Abscess: A Clinical Experience at the University College Hospital Ibadan," Nigeria Journal of Medicine, Vol. 14, No. 4, 2005, pp. 415-418.

[10] C. R. Jennings, "Surgical Anatomy of the Neck," In: G. Michael, Ed., Scott's Browns Otorhinolaryngology, Head and Neck Surgery, 7th Edition, Vol. II, Hodder Arnold, London, 2008, pp. 1744-1745. http://dx.doi.org/10.1201/b15118-153

[11] I. Brook, "Microbiology and Management of Peritonsillar, Retropharyngeal Abscess and Pharyngeal Abscesses," Journal of Oral \& Maxillofacial Surgery, Vol. 62, No. 12, 2004, pp. 1545-1550.

http://dx.doi.org/10.1016/j.joms.2003.12.043

[12] G. J. Ridder, K. Technau-Ihling, A. Sander and C. C. Boedeker, "Spectrum and Management of Deep Neck Space Infections: An 8-Year Experience of 234 Cases," Otolaryngology-Head and Neck Surgery, Vol. 133, No. 5, 2005, pp. 709-714. http://dx.doi.org/10.1016/j.otohns.2005.07.001

[13] J. Stalfors, A. Adielsson, A. Ebenfelt, G. Nethander and T. Westin, "Deep Neck Space Infections Remain a Surgical Challenge. A Study of 72 Patients," Acta Otolaryngology, Vol. 124, No. 10, 2004, pp. 119-1196. http://dx.doi.org/10.1080/00016480410017864

[14] K. Terao, T. Kusunoki, K. Mori. K. Murata and K. Doi, "A Case of Calcific Retropharyngeal Tendinitis: The Significance of Early Diagnosis," Ear, Nose and Throat Journal, Vol. 92, No. 2, 2013, pp. 74-83.

[15] P. J. Schuller, M. Cohen, J. Greve, C. Plettenberg, J. Chereath, M. Wagemann, et al., "Surgical Management of Retropharyngeal Abscess," Acta Oto-Laryngologica, Vol. 129, No. 11, 2009, pp. 1274-1279. http://dx.doi.org/10.3109/00016480802642088

[16] D. K. C. Wong, C. Brown, N. Mills, P. Spielmann and M. Neeff, "To Drain or Not to Drain-Management of Pediatric Deep Neck Abscesses: A Case Conrol Study," International Journal Pediatric Otorhinolaryngology, Vol. 76, No. 12, 2012, pp. 1810-1813.

http://dx.doi.org/10.1016/j.ijporl.2012.09.006

[17] K. Chang, Y. Chen, S. Hao and S. Chen, "UltrasoundGuided Closed Drainage for Abscesses of the Head and Neck," Otolaryngology-Head and Neck Surgery, Vol. 132, No. 1, 2004, pp. 119-124. http://dx.doi.org/10.1016/j.otohns.2004.08.004

[18] M. P. Kamath, K. M. Bhojwani, S. U. Kamath, C. Mahabala and S. Argawal, "Tuberculous Retropharyngeal Abscess," Ear Nose Throat Journal, Vol. 86, No. 4, 2007, pp. 236-237.

[19] H. A. Soub, "Retropharyngeal Abscess Associated with Tuberculosis of Cervical Spine," Tubercle and Lung Disease, Vol. 77, No. 6, 1996, pp. 563-565.

http://dx.doi.org/10.1016/S0962-8479(96)90057-X

[20] A. Christoforidou, S. Metallidis, P. Kollaras, A. Agathangelidis, P. Nikolaidia, V. Vital and K. Markou, "Tuberculous Retropharyngeal Abscess as a Cause of Oropharyngeal Dysphagia," American Journal of OtolaryngologyHead and Neck Medicine and Surgery, Vol. 33, No. 2, 2012, pp. 272-274.

[21] C. Patil, R. Kharat, P. Deshmukh, S. Singhal and B. D'Souza, "Tuberculous Retropharyngeal Abscess without Cervical Spine TB," Asian Pacific Journal of Tropical Medicine, Vol. 4, No. 3, 2011, pp. 251-252. http://dx.doi.org/10.1016/S1995-7645(11)60080-1

[22] H. S. Sharma, D. S. Kurl and M. Hamza, "Retropharyngeal Abscess: Recent Trend," Auris Nasus Larynx, Vol. 25, No. 4, 1998, pp. 403-406. http://dx.doi.org/10.1016/S0385-8146(98)00007-8 